\title{
Influence of Different Seed Rhizome Storage Methods on Viability, Growth and Yield of Turmeric (Curcuma Longa L.)
}

\author{
Masreshaw Yirga \\ Jimma Agricultural Research Center, P. O. Box, 192, Jimma, Ethiopia
}

\begin{abstract}
In spite of the importance of turmeric 'Ird' as a ground spice and in curry powder in Ethiopia and the efforts made so far to generate improved technologies, its production and quality is remained low compared with the world average. One of the contributing factors is lack of appropriate seed rhizome storage methods, which insisted the current investigation. The study was conducted at Metu agricultural research sub center to determine suitable rhizome storage methods on viability, yield and growth parameter in 2017. The experiment was laid out in RCBdesign with 3 replications. This experiment was consisted of twelve treatments which were arranged using 3 planting materials (turmeric mother rhizome, finger Rhizome and mixed rhizome) stored under 4 storage conditions(shade + mulch, nursery + mulch, constructed seed store house, and pit). Analysis of variance revealed significant variation among the treatments for disease incidence $(\mathrm{p}<0.05)$, rhizome length and rhizome yield $(\mathrm{p}<0.01)$, while non significant for other studied parameters. Mother Seed Rhizome turmeric stored under shade tree+mulch gave the maximum sprouting $(88.4 \%)$. The least rotten percentage was found from rhizomes stored under nursery (3.71\%). Moreover, Mother rhizome stored under shade tree recorded maximum yield and all other parameters viz. highest rhizome viability $(94.53 \%)$, tiller per plant $(2.8)$, leaf length $(25.5 \mathrm{~cm})$, leaf width $(14.6 \mathrm{~cm})$, plant height $(28.1 \mathrm{~cm})$, rhizome length $(5.9 \mathrm{~cm})$, rhizome width $(2.0 \mathrm{~cm})$, number of fingers per stood $(5.2 \mathrm{~cm})$ and yield (38.2 ton/hectare). generally shade tree +mulch has produced maximum rhizome sprouting and viability, maximum yield and yield related parameters, therefore this storage method is found the best appropriate rhizome storage method to be used by the users.
\end{abstract}

Keywords: turmeric, rhizome, storage methods, sprouting, viability

DOI: $10.7176 / \mathrm{JEES} / 10-7-01$

Publication date:July $31^{\text {st }} 2020$

\section{Introduction}

Turmeric (curcuma longa) which belongs to the ginger family, zingiberaceae, is a rhizomatous herbaceous plant (Chirangi et al., 2004). It is native to tropical south Asia and shares many similarities to ginger and galangal, demonstrable from the shape of their bulbous rhizomes (roots). Use of turmeric probably traced back nearly 4000years, to the Vedic culture in India, when turmeric was the principal spice and also had religious significance.

The crop is widely used as a spice in Bangladesh India, Myanmar, Pakistan, Sri Lanka and Thailand (Hermann and Martin, 1991; Ishimine et al., 2003). The tuberous rhizomes have been used from Antiquity as a condiment, a textile dye, medicinally as aromatic stimulant, as an ingredient that colors and flavors prepared food. Components of the turmeric care named curcuminiods which include mainly curcumin (diferuloyl methane), demethoxycurcumin and bisdemethoxy-curcumin (Chainani, 2003). Curcuminoids in turmeric have anti-inflammatory, antimutagen, anticancer, antibacterial, anti-fungal, anti-parasitic and detoxifying properties (Hermann and martine, 1991; Nakamura et al., 1998; Osawa et al., 1995; Sugiyama et al.,1996; Uechi et al., 2000). Turmeric consists of $3-5 \%$ curcuminiods. Curcumin is the most important fraction which is responsible for biological activities of turmeric. Curcumin and volatile oils of turmeric prevent tumor formation, improve liver and kidney functions and could be used against biliary disorders, diabetic and hepatic disorder (Hermann and Martine, 1991).

Turmeric is cultivated in a very similar way to its close relative, ginger. Both are perennial plants, but are cultivated as annuals. In other words, although they would survive in the ground for several years, they are sown and harvested every year. They are propagated using "seed rhizomes" that are kept aside for replanting during each year harvest. Turmeric thrive best in the hot humid agro-ecology and needs temperature between $20{ }^{\circ} \mathrm{C}$ and $30{ }^{\circ} \mathrm{C}$ and considerable annual rainfall.

Turmeric 'Ird' in Ethiopia used as a ground spice and in curry powder, mainly as a food-coloring agent as well as a coloring material in the textile industry. Before, 1972, Ethiopia was one of turmeric importing country. Then gradually, the county stated producing turmeric by starting turmeric breeding through introduction of turmeric varieties from India and China in 1972. The introduced materials were planted at Jimma, Metu,Bebeka, Tepi, Wenago ,Awasa, and Bako to evaluated and identify suitable varieties adaptable to different environmental conditions of Ethiopia, and at the same time to identify potential areas for turmeric production in the country. The introduced genotypes were performed well in all testing locations. Consequently, during the previous decades of turmeric breeding research effort two varieties were released for their suitable agro-ecologies. Turmeric in Ethiopia can be grown up to an altitude of 2000m.a.sl. Currently, the crop is widely grown and becoming important cash crop for farmers and large scale producers in south western Ethiopia humid agro-ecology (Edosa, 1998; Girma et 
al., 2008a).

Girma (2016) reported that, average productivity of turmeric dry rhizome yield was 4.2-5.3 ton/hectare at research center, while 3.20-4.2 ton /hectare at farmer's field. Although this spice crop is very important for changing the livelihood of Small scale farmers in southwestern part of Ethiopia, the challenge for turmeric production is its quality that could be governed by the cultivar grown, the stage of rhizome maturity at harvest and traditional production and processing practices. In Ethiopia, Traditional and Poor quality processing practices carried out by growers are the main factors for inferior quality spice products which make unable to compete in local and international markets (Fantahun and Teklu, 1995).

One of the main contributing factors for such low quality product has been absence of appropriate harvesting stage and seed rhizome storage methods to get the optimum yields extracts (oleoresin and volatile oil content) and other quality parameters. Farmer usually planted turmeric by using the seed rhizomes which are left in the ground or kept in the field for a period of time before planting for the next growing season. Thus, such a kind storage system wills exposure of the cutting to the sun which results in lost viability within a short time due to dehydration. These poor stakes cause a poor establishment and finally a low yield and quality products of turmeric. Even though appropriate post harvest storage recommendation is very important for production and productivity of quality turmeric, suitable post harvest storage recommendation for the next planting material has been not yet studied in Ethiopia. Therefore this experiment was conducted to identify appropriate pr-planting storage methods for maximum production and productivity of turmeric.

\section{Materials and methods}

Experimental site and Design: The experiment was conducted under rainfed condition at Metu Agricultural Research Sub Center during 2017 cropping season. The sub-center is located $600 \mathrm{~km}$ away from Addis Ababa in Illubabor zone of the Oromia Regional State. Metu is located on latitude $8^{\circ} 19^{\prime} 0^{\prime \prime} \mathrm{N}$ longitude $35^{\circ} 35^{\prime} 0^{\prime \prime} \mathrm{E}$ at an altitude of 1558 m.a.s.l. The mean annual temperature ranges from 12.7 and $28.9^{\circ} \mathrm{C}$ with annual rainfall of 1829 $\mathrm{mm} /$ annum. The major soil type is Nitosols with pH of 5.24 and phosphorus level of $9.36 \mathrm{ppm}$ (Paulos, 2001).

Experimental Design, Materials and Field Management: The experiment was laid out in randomized complete block design with four replications. A Turmeric commercial variety named Dame was tested in this study. This experiment was consisted of twelve treatments which included 3 planting materials (mother rhizome, finger Rhizome and mixed rhizome) stored under4 storage conditions (shade + mulch, nursery + mulch, seed store house, and pit).

The treatment were arranged as follows : Turmeric mother seed rhizome heaped under shade tree and mulched (TMSRHS), Turmeric finger seed rhizome heaped under shade tree and mulched (TFSRHS), Turmeric mother and finger seed rhizomes heaped under shade tree and mulched (TMFSRHS), Turmeric mother seed rhizomes heaped under nursery shade and mulched (TMSRHN), Turmeric finger seed rhizomes heaped under nursery shade and mulched (TFSRHN), turmeric mother and finger seed rhizomes heaped under nursery shade and mulched (TMFSRHN), Turmeric mother seed rhizome stored under constructed seed store house healed on bed (TMSRSH),Turmeric finger seed rhizome stored under constructed seed store house healed on bed (TFSRSH), Turmeric mother and finger seed rhizomes stored under constructed seed store house healed on bed (TMFSRSH), Turmeric mother seed rhizomes stored under PIT (TMSRSP), Turmeric finger seed rhizomes stored under PIT (TFSRSP), Turmeric mother-finger seed rhizomes stored under PIT (TMFSRSP).

During harvesting time, $15 \mathrm{~kg}$ of Seed rhizome was taken from each rhizome planting materials and stored from January-march according to the methods described above. For each treatments $15 \mathrm{~kg}$ seed rhizome were used. Treatments were field planted during April with the spacing of $30 \mathrm{~cm}$ between rows and $15 \mathrm{~cm}$ between plants. All other management practices were also uniformly applied for the experiment as per turmeric agronomic production practices.

Data collection and analysis: Before planting percent of rotted sprouted, shriveled and viable data were recorded. During growth stage and harvesting time different yield and growth parameter data were collected from stand count, number of tiller per plant, leaf width, leaf length, plant height, disease incidence, rhizome length, rhizome width, number finger rhizome per seed and rhizome yield per plant. Prior to statistical analysis normality test of the data was performed and then subjected to analysis of variance using the SAS software.

\section{Result and discussion}

Analysis of variance (ANOVA) revealed significant variation among the treatments for disease incidence $(p<0.05)$, rhizome length and rhizome yield $(\mathrm{p}<0.01)$, while non significant for other studied parameters (Table 1$)$ 
Table 1. Mean squares of analysis of variance for yield and related characters of ten soybean genotypes at Metu during 2017

\begin{tabular}{|ccccccccccccc|}
\hline source & DF & VP & SC & NTPP & LW & LL & PH & DI & RL & RW & NFPS & YLD \\
\hline Rep & 2 & $98.1^{*}$ & $392.2^{*}$ & 0.1 & 28.0 & $140.8^{* *}$ & 14.3 & 306.3 & $1.3^{*}$ & 0.036 & 0.1 & 0.2 \\
Trt & 11 & 31.3 & 125.2 & 0.2 & 10.3 & 23.6 & 12.5 & $538.6^{*}$ & $0.99^{* *}$ & 0.035 & 4.0 & $95.0^{* *}$ \\
error & 22 & 28.5 & 113.7 & 0.3 & 20.1 & 17.7 & 8.78 & 188 & 0.19 & 0.02 & 0.47 & 12.2 \\
\hline
\end{tabular}

$*, * *$ significant at $5 \%$ and $1 \% *$ probability level, respectively, others non significant, $\mathrm{DF}=$ degree of freedom, $\mathrm{VP}=$ Viability percentage, $\mathrm{SC}=$ stand count, $\mathrm{NTPP}=$ number of tiller per plant, $\mathrm{LW}=$ leaf width, $\mathrm{LL}=$ leaf length, $\mathrm{PH}=$ plant height, $\mathrm{DI}=$ disease incidence, $\mathrm{RL}=$ rhizome length, $\mathrm{RW}=$ rhizome width, $\mathrm{NFRS}=$ number finger rhizome per stood and YLD=rhizome yield per hectare

Turmeric rhizomes stored under different storage methods had significant effect on sprout and rhizome seed quality of turmeric. Seed Rhizome turmeric stored under shade tree+mulch gave the maximum sprouting $(60.29 \%)$, followed by rhizome stored under pit $(53.33 \%)$, the possible reason may be due to the presence of considerable amount of air, moisture and temperate relative to the store house and nursery. Optimum light is also an important factor in newly sprouts to maintaining the rhizome moisture content compared to the low light intensity perceived by the sprouts of rhizome. In this experiment, it was found that rhizome stored in the constructed store house followed by nursery was found dried and shriveled, which might result in lower moisture content. In these storage methods rhizomes were produced some bud like sprouting with pale and yellow color. In all of the cases, mother rhizome gave the maximum sprouting than finger and mixed rhizome stored under different storage methods (table 2). The highest rotten percentage was recorded from rhizomes stored under constructed seed store house and shade tree with mulch, which might be lack of optimum aeration in case of store house and mulch creates conducive environment for fungal development under shade tree. The list rotten percentage was found from rhizomes stored under nursery; probably the environment may not be favorable for fungal development. This result was agreement with the finding Hailemichael and Seyoum (2016) who did their research on evaluation of different storage method on viability and field estbilishement of ginger, which is close relative of turmeric.

Table 3. Effect of different turmeric seed storage methods (shade + mulch, nursery + mulch, seed store house, and pit) on sprout and rhizome seed quality

\begin{tabular}{|c|c|c|c|c|c|c|c|}
\hline trt & $\begin{array}{c}\text { Total } \\
\mathbf{( k g )}\end{array}$ & $\begin{array}{c}\text { Sprout } \\
\mathbf{( k g )}\end{array}$ & $\begin{array}{c}\text { Sprout } \\
\mathbf{\%}\end{array}$ & $\begin{array}{c}\text { non sprout } \\
\mathbf{( k g )}\end{array}$ & $\begin{array}{c}\text { non sprout } \\
\mathbf{\%}\end{array}$ & $\begin{array}{c}\text { Rotten } \\
(\mathbf{k g})\end{array}$ & $\begin{array}{c}\text { Rotten } \\
\mathbf{\%}\end{array}$ \\
\hline MRHS & 3579.00 & 3164.00 & 88.40 & 365.00 & 10.20 & 50.00 & 1.40 \\
\hline FRHS & 3078.00 & 1295.00 & 42.07 & 991.00 & 32.20 & 792.00 & 25.73 \\
\hline MFRHS & 2823.00 & 1423.00 & 50.41 & 780.00 & 27.63 & 620.00 & 21.96 \\
\hline Mean(shade tree) & $\mathbf{3 1 6 0 . 0 0}$ & $\mathbf{1 9 6 0 . 6 7}$ & $\mathbf{6 0 . 2 9}$ & $\mathbf{7 1 2 . 0 0}$ & $\mathbf{2 3 . 3 4}$ & $\mathbf{4 8 7 . 3 3}$ & $\mathbf{1 6 . 3 6}$ \\
\hline MRHN & 2520.00 & 1250.00 & 49.60 & 1270.00 & 50.40 & 0.00 & 0.00 \\
\hline FRHN & 2469.00 & 502.00 & 20.33 & 1692.00 & 68.53 & 275.00 & 11.14 \\
\hline MFRHN & 2525.00 & 782.00 & 30.97 & 1743.00 & 69.03 & 0.00 & 0.00 \\
\hline Mean(nursery) & $\mathbf{2 5 0 4 . 6 7}$ & $\mathbf{8 4 4 . 6 7}$ & $\mathbf{3 3 . 6 3}$ & $\mathbf{1 5 6 8 . 3 3}$ & $\mathbf{6 2 . 6 5}$ & $\mathbf{9 1 . 6 7}$ & $\mathbf{3 . 7 1}$ \\
\hline TMRSH & 2360.00 & 1010.00 & 42.80 & 1230.00 & 52.12 & 120.00 & 5.08 \\
\hline FRSH & 2692.00 & 932.00 & 34.62 & 1368.00 & 50.82 & 392.00 & 14.56 \\
\hline MFRSH & 2825.00 & 948.00 & 33.56 & 1521.00 & 53.84 & 356.00 & 12.60 \\
\hline Mean(store house) & $\mathbf{2 6 2 5 . 6 7}$ & $\mathbf{9 6 3 . 3 3}$ & $\mathbf{3 6 . 9 9}$ & $\mathbf{1 3 7 3 . 0 0}$ & $\mathbf{5 2 . 2 6}$ & $\mathbf{2 8 9 . 3 3}$ & $\mathbf{1 0 . 7 5}$ \\
\hline MRSP & 2974.00 & 1933.00 & 65.00 & 990.00 & 33.29 & 51.00 & 1.71 \\
\hline FRSP & 2976 & 1456 & 48.92 & 1300 & 43.68 & 220 & 7.39 \\
\hline MFRSP & 2898 & 1335 & 46.07 & 1515 & 52.28 & 48 & 1.66 \\
\hline Mean(pit) & $\mathbf{2 9 4 9 . 3 3}$ & $\mathbf{1 5 7 4 . 6 7}$ & $\mathbf{5 3 . 3 3}$ & $\mathbf{1 2 6 8 . 3 3}$ & $\mathbf{4 3 . 0 8}$ & $\mathbf{1 0 6 . 3 3}$ & $\mathbf{3 . 5 9}$ \\
\hline Over all mean & $\mathbf{2 8 0 9 . 9 2}$ & $\mathbf{1 3 3 5 . 8 3}$ & $\mathbf{4 6 . 0 6}$ & $\mathbf{1 2 3 0 . 4 2}$ & $\mathbf{4 5 . 3 4}$ & $\mathbf{2 4 3 . 6 7}$ & $\mathbf{8 . 6 0}$ \\
\hline
\end{tabular}

MRHS=mother rhizome heaped under shade tree and mulched, FRHS= finger rhizome heaped under shade tree and mulched, MFRHS=mother and finger seed rhizomes heaped under shade tree and mulched, MRHN $=$ mother rhizomes heaped under nursery shade and mulched, MRHN=finger rhizomes heaped under nursery shade and mulched, FRHN = finger rhizomes heaped under nursery shade and mulched, MFRHN= mother and finger seed rhizomes heaped under nursery shade and mulched, $\mathrm{MRSH}=$ mother seed rhizome stored under constructed seed store house healed on bed, FRSH= finger rhizome stored under constructed seed store house healed on bed, $\mathrm{MFRSH}=$ mother and finger seed rhizomes stored under constructed seed store house healed on bed, MRSP= mother seed rhizomes stored under pit, FRSP $=$ finger rhizomes stored under pit, MFRSP $=$ mother finger seed rhizomes stored under Pit

Different storage methods had significant effect on yield and other growth parameters of turmeric. Due to higher sprouting percentage $(60 \%)$, turmeric rhizomes stored under shade tree + mulch produced the highest viability $(93.5 \%)$ than other storage methods. This storage method as well give maximum number of tiller per 
plant (2.6), longest leaf length $(25.0 \mathrm{~cm})$ and wider leaf width $(14.3 \mathrm{~cm})$, tallest plant height $(27.3 \mathrm{~cm})$, longest rhizome length $(5.6 \mathrm{~cm})$ and wider rhizome $(1.9 \mathrm{~cm})$, maximum number of fingers per stood (5.1) (Table 2.).

Table 2. Effect of different storage methods (shade + mulch, nursery + mulch, seed store house, and pit) on viability, yield and different growth parameters of turmeric at Metu in2017

$\mathrm{PP}=$ plant population, $\mathrm{NTPP}=$ number of tiller per plant, $\mathrm{LW}=$ leaf width, $\mathrm{LL}=$ leaf length, $\mathrm{PH}=$ plant height,

\begin{tabular}{|ccccccccccc|}
\hline TRT & $\begin{array}{c}\text { PP } \\
(\mathbf{\%})\end{array}$ & NTPP & $\begin{array}{c}\text { LW } \\
(\mathbf{c m})\end{array}$ & $\begin{array}{c}\text { LL } \\
(\mathbf{c m})\end{array}$ & $\begin{array}{c}\text { PH } \\
(\mathbf{c m})\end{array}$ & $\begin{array}{c}\text { DI } \\
(\mathbf{\%})\end{array}$ & $\begin{array}{c}\text { RL } \\
(\mathbf{c m})\end{array}$ & $\begin{array}{c}\text { RW } \\
(\mathbf{c m})\end{array}$ & NFPS & $\begin{array}{c}\text { YLD } \\
(\mathbf{t} / \mathbf{h a})\end{array}$ \\
\hline MRHS & 94.3 & 2.8 & 14.6 & 25.5 & 28.1 & 71.7 & 5.9 & 2.0 & 5.2 & 38.2 \\
FRHS & 93.5 & 2.5 & 14.2 & 25.1 & 27.3 & 68.3 & 5.5 & 1.9 & 5.1 & 36.7 \\
MFRHS & 92.7 & 2.5 & 14.0 & 24.3 & 26.6 & 68.3 & 5.5 & 1.9 & 4.9 & 35.1 \\
\hline Mean(shadetree) & $\mathbf{9 3 . 5}$ & $\mathbf{2 . 6}$ & $\mathbf{1 4 . 3}$ & $\mathbf{2 5 . 0}$ & $\mathbf{2 7 . 3}$ & $\mathbf{6 9 . 4}$ & $\mathbf{5 . 6}$ & $\mathbf{1 . 9}$ & $\mathbf{5 . 1}$ & $\mathbf{3 6 . 7}$ \\
\hline MRHN & 92.2 & 2.3 & 13.6 & 24.2 & 26.5 & 63.3 & 5.3 & 1.8 & 4.7 & 34.7 \\
FRHN & 91.5 & 2.3 & 13.5 & 23.3 & 25.8 & 61.7 & 5.2 & 1.8 & 4.7 & 29.4 \\
MFRHN & 91.5 & 2.2 & 11.9 & 22.7 & 25.3 & 60.0 & 4.8 & 1.8 & 4.6 & 28.4 \\
\hline Mean(nursery) & $\mathbf{9 1 . 7}$ & $\mathbf{2 . 3}$ & $\mathbf{1 3 . 0}$ & $\mathbf{2 3 . 4}$ & $\mathbf{2 5 . 8}$ & $\mathbf{6 1 . 7}$ & $\mathbf{5 . 1}$ & $\mathbf{1 . 8}$ & $\mathbf{4 . 7}$ & $\mathbf{3 0 . 9}$ \\
\hline TMRSH & 90.0 & 2.2 & 11.6 & 21.7 & 25.0 & 58.3 & 4.7 & 1.8 & 4.6 & 28.1 \\
FRSH & 89.2 & 2.2 & 11.0 & 21.4 & 24.2 & 58.3 & 4.7 & 1.7 & 4.6 & 27.2 \\
MFRSH & 88.2 & 2.1 & 10.9 & 20.7 & 23.0 & 50.0 & 4.6 & 1.7 & 4.5 & 24.2 \\
\hline Mean(storehouse) & $\mathbf{8 9 . 1}$ & $\mathbf{2 . 2}$ & $\mathbf{1 1 . 2}$ & $\mathbf{2 1 . 3}$ & $\mathbf{2 4 . 1}$ & $\mathbf{5 5 . 6}$ & $\mathbf{4 . 7}$ & $\mathbf{1 . 7}$ & $\mathbf{4 . 6}$ & $\mathbf{2 6 . 5}$ \\
\hline MRSP & 88.0 & 2.0 & 10.6 & 18.9 & 22.8 & 46.7 & 4.5 & 1.7 & 4.5 & 23.3 \\
FRSP & 85.2 & 2.0 & 10.0 & 17.5 & 22.5 & 33.3 & 4.2 & 1.7 & 4.4 & 23.2 \\
MFRSP & 84.0 & 2.0 & 9.2 & 17.5 & 19.8 & 30.0 & 4.0 & 1.6 & 4.1 & 22.6 \\
\hline Mean(pit) & $\mathbf{8 5 . 7}$ & $\mathbf{2 . 0}$ & $\mathbf{9 . 9}$ & $\mathbf{1 7 . 9}$ & $\mathbf{2 1 . 7}$ & $\mathbf{3 6 . 7}$ & $\mathbf{4 . 3}$ & $\mathbf{1 . 6}$ & $\mathbf{4 . 4}$ & $\mathbf{2 3 . 0}$ \\
\hline Over all mean & $\mathbf{9 0 . 0}$ & $\mathbf{2 . 3}$ & $\mathbf{1 2 . 1}$ & $\mathbf{2 1 . 9}$ & $\mathbf{2 4 . 7}$ & $\mathbf{5 5 . 8}$ & $\mathbf{4 . 9}$ & $\mathbf{1 . 8}$ & $\mathbf{4 . 7}$ & 29.3 \\
CV \% & $\mathbf{5 . 9}$ & $\mathbf{3 3 . 5}$ & $\mathbf{3 7 . 1}$ & $\mathbf{1 9 . 2}$ & $\mathbf{1 1 . 7}$ & $\mathbf{2 4 . 6}$ & $\mathbf{8 . 8}$ & $\mathbf{7 . 9}$ & $\mathbf{1 4 . 6}$ & 11.9 \\
Significance & $\mathbf{n s}$ & $\mathbf{n s}$ & $\mathbf{n s}$ & $\mathbf{n s}$ & $\mathbf{n s}$ & $* *$ & $\mathbf{0 . 7}$ & $\mathbf{n s}$ & $\mathbf{n s}$ & $* *$ \\
LSD 5\% & $\mathbf{9 . 0}$ & $\mathbf{1 . 0}$ & $\mathbf{7 . 6}$ & $\mathbf{7 . 1}$ & $\mathbf{5 . 0}$ & $\mathbf{2 3 . 2}$ & $\mathbf{0 . 7}$ & $\mathbf{0 . 2}$ & $\mathbf{1 . 2}$ & 5.9 \\
\hline
\end{tabular}

$\mathrm{DI}=$ disease incidence, $\mathrm{RL}=$ rhizome length, $\mathrm{RW}=$ rhizome width, $\mathrm{NFRS}=$ number finger rhizome per stood and $\mathrm{YLD}=$ rhizome yield per hectare

Conversely, these considerable viability and growth parameters resulted, maximum rhizome yield (36.7 ton/hectare). Moreover, different turmeric rhizomes (mother, finger and mixed) stored under different storage methods had also considerable effect on yield and other growth parameters of turmeric. Mother rhizome stored under shade tree found the highest yield and all other growth parameters viz. highest rhizome viability $(94.53 \%)$, tiller per plant $(2.8)$, leaf length $(25.5 \mathrm{~cm})$, leaf width $(14.6 \mathrm{~cm})$, plant height $(28.1 \mathrm{~cm})$, rhizome length $(5.9 \mathrm{~cm})$, rhizome with $(2.0 \mathrm{~cm})$, number of fingers per stood $(5.2 \mathrm{~cm})$ and yield $(38.2 \mathrm{ton} /$ hectare) (table 2). The current finding is consistent with the report of previous authors (Aiyadurai, 1966; Purseseglove et al., 1981; Hailemichael and Seyoum, 2016) who investigated effect of different storage methods on its close relative crop; ginger field establishment, yield and growth parameters.

\section{Conclusion}

Appropriate Storage of turmeric seed rhizome before planting is an important factor to determine better field establishment, viability, yield and other growth parameters of turmeric. The result indicated that mother Seed Rhizome turmeric stored under shade tree+mulch gave the maximum sprouting (88.4\%).The least rotten percentage was found from rhizomes stored under nursery (3.71\%). Moreover, Mother rhizome stored under shade tree recorded maximum yield and all other parameters. generally shade tree + mulch has produced maximum rhizome sprouting and viability, maximum yield and yield related parameters, therefore this storage method is found the best appropriate rhizome storage method to be used by the users followed by nursery + mulch storage method.

\section{Reference}

Aiyaduri, S.G. 1966. A Review of Research on spice and cashew nut in India., Ernakulam-6; Indian Council of Agric. Res. Pp. 228.

Edossa E (1998). Spices research achievements and experiences, research report No.33. Institute of Agricultural Research, Addis Ababa Ethiopia.

Fantahun L, Teklu N (1995). Spices crops processing: constraints and possibilities, Workshop on Coffee and Associated Crops, Feb. 27 - March 1/1995. Addis Ababa Ethiopia, pp 1-19.

Girma H, Digafie T, Edossa E, Belay YB, Weyessa G (2008). Spices research achievements, revised edition, Ethiopian Institute of Agricultural Research, Addis Ababa Ethiopia, pp 7-25. 
Hailemichael G, Seyoum M (2016). Influence of Different Storage Methods on the Viability and Field Establishment of Seed Rhizome Ginger (Zingiber officinale Rosc.) in Ethiopia. Acad. Res. J. Agri. Sci. Res. 4(4): 117-123

Hermann, P. T. A. and Martin, A. W. 1991. Pharmacology of Curcuma longa. Planta Med. 57 : 1-7.

Ishimine, Y., Hossain, M. A., Ishimine, Y. and Murayama, S. 2003. Optimal planting depth for turmeric (Curcuma longa L.) cultivation in dark red soil in Okinawa Island, Southern Japan. Plant Prod. Sci. 6 : 83-89.

Nakamura, Y., Ohto, Y., Murakami, A., Osawa, T. and Ohigashi, H. 1998. Inhibitory effects of curcumin andtetrahydrocurcuminoids on tumor promoter-induced reactive oxygen species generation in leukocytes in vitro and in vivo.Jpn. J. Cancer Res. 89 : 361-370.

Osawa, T., Sugiyama, Y., Inayoshi, M. and Kawakishi, S. 1995. Antioxidative activity of tetrahydrocurcuminoids. Biosci.

Biotech. Biochem. 59 : 1609-1612.

Purseglove JW, Brown EG, Green CL, Robins SRJ (1981). Spices, volume 2. Longman Group Limited, London.

Sugiyama, Y., Kawakishi, S. and Osawa, T. 1996. Involvement of the $\beta$-diketone moiety in the antioxidative mechanism oftetrahydrocurcumin. Biochem. Pharmacol. 52 : 519-525.

Uechi, S., Miyagi, Y., Ishimine, Y. and Hongo, F. 2000.Antibacterial activity of essential oils from Curcuma sp.(Zingiberaceae) cultivated in foodborne pathogenic bacteria.Jpn. J.Trop. Agr. 44 : 138-140. 